This paper is copyright of the author and of Cambridge University Press. Available with kind permission of Cambridge University Press.

Please go to http://journals.cambridge.org for further information.

\title{
Taking the trivial doctrine seriously: Functionalism, eliminativism, and materialism
}

\author{
Maurizio Tirassa \\ Università di Torino - Centro di Scienza Cognitiva \\ via Lagrange, 3 - 10123 Torino (Italy) \\ email tirassa@psych.unito.it
}

\begin{abstract}
Gold \& Stoljar's characterization of the trivial doctrine and of its relationships with the radical one misses some differences that may be crucial. The radical doctrine can be read as a derivative of the computational version of functionalism that provides the backbone of current cognitive science and is fundamentally uninterested in biology: both doctrines are fundamentally wrong. The synthesis between neurobiology and psychology requires instead that minds be viewed as ontologically primitive, that is, as material properties of functioning bodies. G\&S's characterization of the trivial doctrine should therefore be correspondingly modified.
\end{abstract}

Gold \& Stoljar (1999; henceforth, G\&S) contrast two versions of the neuron doctrine, the claim that scientific understanding of the mind will come from neurobiology. In the trivial version, understanding will require the synthesis of neurobiology and psychology; according to G\&S, this reading of the neuron doctrine is uncontroversial and widely accepted in cognitive science. The radical version is instead eliminativist: it can be clearly distinguished, at least in general, from the trivial one, and G\&S prove it wrong by showing that precisely the psychological concepts it rejects are instead necessary in neurobiology.

This picture, however, misses some differences that may be crucial. The backbone of cognitive science is currently provided by a doctrine, computational functionalism, that has nothing to do with biology, which it views as just implementation, that is, accidental. Furthermore, this doctrine has close (albeit seldom acknowledged) relationships with eliminativism. G\&S's characterization of the trivial doctrine as the assembly of all non-eliminativist views of cognition blurs the difference between the biologically inspired and the classically computational views of cognition and should therefore be correspondingly modified.

That the computer metaphor lies at the heart of most contemporary studies of the mind hardly seems debatable: talk of cognition as computation is commonplace both in the symbolic and in the connectionist literature, albeit with different specifications, and so is the tenet that the architecture of the mind is that of an information-processing system. (Let us set aside the exhausting discussions of precisely what sort of information-processing system the mind is supposed to be.) It is constitutive of this perspective that the mind is an abstract description of the physical machine that happens to "implement" cognition. The doctrine of multiple realizability is the natural, if sometimes disowned, child of this view.

Computational functionalism is generally held to be the opposite of eliminativism; indeed, this seems to be G\&S's view as well when they exclude from their characterization of the trivial doctrine only "a certain version of artificial intelligence" (sect. 2.2.1, para. 7). As the mind is 
stripped of its ontological primitivity, however, the radical doctrine loses much of its radicality and unreasonableness: after all, if the mind is only an abstract level of description, why should cognitive scientists not simply do away with it and focus instead on the concrete physical machine? Eliminativism is another natural child of computationalism - though, again, one that is often disowned. (There is no space here to discuss how it relates to the doctrine of multiple realizability).

Should this reading appear somewhat wicked, reconsider in its light the quotation that G\&S make from Higginbotham ${ }^{1}$ (1990): "...the study of the mind is the study of the brain and nervous system, conducted at some level of abstraction that we would like to clarify" (sect. 2.2.1, para. 4).

To make another example, suppose that, thanks to some novel mathematical approach, a yetto-be-devised non-associative connectionist network proves capable of satisfactory grammatical parsing: would this not be a proof, to those who endorse computational functionalism, that the alleged abstract level of description is fundamentally useless, and thus count as a match point for the radical doctrine that minds are but the folk postulates of an immature science? (According to the account that the mind is a computational device implemented in the brain, such a hypothetical network must be at least a possibility, if computationalism is not to espouse dualism. The insufficiencies of current connectionism thus cannot be used to do away with this point).

The only way out of these two related versions of eliminativism (computational functionalism and G\&S's radical doctrine) is to acknowledge that minds are ontologically primitive rather than disposable high-level descriptions of what is actually occurring at the physical level. Unless one is willing to be a dualist, this position in turn entails that minds must be conceived of as material properties of functioning brains (or, better still, functioning bodies). As with all natural phenomena, minds can of course be described, but they are not themselves levels of descriptions.

To resume, the situation is much more complex and articulated, and more controversial, than can be captured with the dichotomy between mentalism and eliminativism, unless careful constraints are imposed on what view of the mind counts as non-eliminativist. In particular, what G\&S call the trivial doctrine comes in two quite different versions that should not be conflated. One version endorses what seems to me (and to G\&S) the main tenet of materialist cognitive science, namely, the idea that neurobiology and psychology should proceed toward a non-dualist, non-eliminativist synthesis. This doctrine will turn out to be correct in one or another of its possible versions and has all the substantive consequences one might desire, concerning in particular the plausibility of computationalism and the role of formal tools and externalized codes in the study of cognition.

Most cognitive scientists, however, seem to endorse a different version of the trivial doctrine, one that builds on the computational version of functionalism that has so pervasively shaped the development of our discipline and that, viewing biology as implementation, is fundamentally uninterested in it. The radical doctrine may be viewed as a consequent, albeit somewhat perverted, derivative of this stance, and both are fundamentally mistaken.

\section{References}

Gold, I., Stoljar, D. (1999) A neuron doctrine in the philosophy of neuroscience. Behavioral and Brain Sciences 22: 809-869.

Higginbotham, J. (1990) Philosophical issues in the study of language. In: Language: an invitation to cognitive science, eds. D.N. Osherson \& H. Laznik. Cambridge, MA: MIT Press.

\footnotetext{
${ }^{1}$ My point is not particularly aimed at Higginbotham's work or at linguistics in general: analogous statements abound in the literature on the philosophy of cognitive science as well as in textbooks and introductions to the field.
} 